Structural Change and Economic Dynamics, vol. 2, no. 2, 1991

\title{
ENVIRONMENT AND ECONOMICS
}

\author{
FAYE DUCHIN, ${ }^{1}$ BERT STEENGE ${ }^{2}$ AND ALESSANDRO \\ VERCELLI ${ }^{3}$
}

In the introduction to the special theme of the last issue of SCED, various approaches to structural and dynamic analysis were discussed, and responses to changes in parameters or exogenous variables were investigated. In that issue the emphasis was on the theoretical analysis of the dynamics of economic systems.

One of the main sources of change at the present time is the relationship between economic structures and the natural environment. After a period of interest in and debate on the subject of natural resource scarcity in the late $1960 \mathrm{~s}$ and early 1970s (e.g. the controversy surrounding the Club of Rome report), public and professional interest shifted to different topical issues such as energy prices and the foreign debt of developing countries. Of course, work on optimal extraction of resources and optimal pricing policies for externalities both preceded and followed this period.

In the 1980 s economists became increasingly concerned about global environmental problems, realizing that they were strictly intertwined with the basic structural features of development. These concerns were popularized in the Brundtland Report and reflected in the renewed interest in economic models of the world economy (such as the LINK model and the World Input-Output Model). In this period there has been a flourishing of initiatives such as the establishment of new scientific journals and research institutes devoted to the interactions between the economy and the environment. This is a research area where new information, insights, and methods are required.

The special theme of this issue includes a set of papers aiming to stimulate new research in this field. The theoretical and methodological themes treated in this journal may contribute to a better understanding of the environmental problems and to an improvement in current approaches to analysing and addressing them. For example, some of the topics discussed in the preceding special theme issue, such as the appropriate level of aggregation, and concepts of equilibrium and stability, are also encountered in examining resource extraction, the use of the environment's assimilation capacity, and pollutant emissions resulting in acid rain and possible climate modification. The papers in this issue illustrate some of the efforts and misgivings characteristic of the work currently being carried out. Not all the approaches of interest are covered, but we intend to continue to publish articles in this area.

Addresses: ${ }^{1}$ Institute for Economic Analysis, New York University, USA; ${ }^{2}$ University of Twente, Netherlands; and ${ }^{3}$ University of Siena, Italy. 
Robert Ayres' paper discusses the time-scale of economic adjustment mechanisms and describes the unsustainability of present production methods, which depend on exhaustible stocks and the capacity for waste assimilation of the natural environment. While the familiar substitution mechanisms may be capable of preventing certain instances of depletion and pollution, they are ineffective in the case of market failures which can result in the deterioration of ecosystems by acid rain, and through deforestation and erosion. Incentives for change can readily be designed, but their effects need to be correctly anticipated and existing institutions may be unable to assure their successful implementation.

Charles Perrings addresses the problem of sustainability by means of a control model incorporating threshold levels for specific environmental assets. Ecological sustainability is shown to be possible only under certain stringent conditions. Since market prices reflect scarcity only imperfectly, and this goal cannot necessarily be achieved by means of economic incentives, a significant burden is placed on public policy. In particular, the author clarifies the implications of the fact that the system may be only partly observable and controllable. He shows that under certain conditions an environmental stabilization policy is possible through physical restrictions on economic activity.

There is a clear need for new and systematic information of various sorts if theory is to be put into practice in modelling and policy. In this context, much attention has been paid to whether or not the current indices of national income are good measures of national wealth. Martin Weale shows that national income accounting has evolved significantly since its inception. First developed in the early 1940s, it was substantially modified with the UN System of National Accounts (SNA) in 1968. Weale's paper discusses the conceptual basis for a system of physical resource accounts integrated within the SNA system. A numerical example for Indonesia is developed to demonstrate its use.

Specific patterns of economic and environmental problems can be identified in different parts of the world. The particular problems of developing countries have attracted a lot of attention while those of Eastern Europe, which are taken up in the paper of Albert Steenge, are only beginning to be examined in a coherent way. The paper surveys the huge environmental problems faced by these countries and provides an explanation which takes account of their institutional features. The potential success of international cooperation schemes is undermined by the disastrous loss of competitiveness of East European industries. The paper goes on to suggest the need for a new approach by the relatively rich countries in helping to resolve these problems.

Robert Costanza's paper (in the new section on research problems) takes up some of the themes discussed in the other papers within the framework of a comprehensive although controversial research programme. One of his concerns is ensuring the compatability of local, short-term goals with global, long-term objectives and setting priorities for local, national, and global management of ecological and environmental problems. He proposes the creation of a new field, based on extensive collaboration across the boundaries of existing disciplines, 
called Ecological Economics. Costanza discusses the main objectives of this new field and sketches a working agenda.

The papers of this special theme section suggest that environmental processes interact with all the other aspects of structural change and need to be viewed in a global context. All the authors seem to agree that the traditional economic incentives are not sufficient to achieve the systemic changes required for slowing down potentially irreversible environmental transformations. In particular, it cannot be expected that market forces alone will bring about satisfactory patterns of development. Changes of a more radical nature may be required which will involve technological and institutional transformations. 